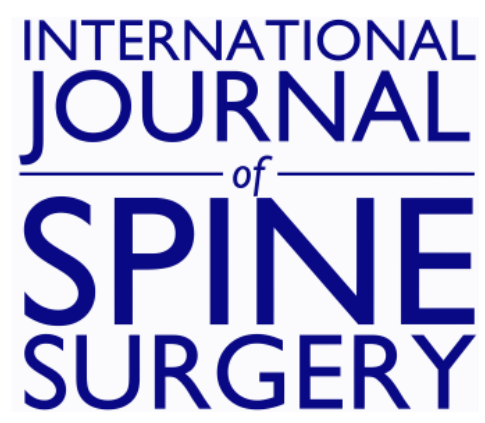

\title{
A Comparison of Surgical Outcomes Between Minimally Invasive and Open Thoracolumbar Corpectomy
}

EHSAN TABARAEE, JUNYOUNG AHN, KHALED ABOUSHAALA and KERN SINGH

Int J Spine Surg 2020, 14 (5) 736-744

doi: https://doi.org/10.14444/7106

http://ijssurgery.com/content/14/5/736

This information is current as of April 26, 2023.

Email Alerts Receive free email-alerts when new articles cite this article. Sign up at:

http://ijssurgery.com/alerts

The International Journal of Spine Surgery

2397 Waterbury Circle, Suite 1,

Aurora, IL 60504, Phone: +1-630-375-1432

(C) 2020 ISASS. All Rightss Refseryedefom http://ijssurgery.com/ by guest on April 26, 2023 


\title{
A Comparison of Surgical Outcomes Between Minimally Invasive and Open Thoracolumbar Corpectomy
}

\author{
EHSAN TABARAEE, MD, JUNYOUNG AHN, MD, KHALED ABOUSHAALA, MD, KERN SINGH, MD \\ Department of Orthopaedic Surgery, Rush University Medical Center, Chicago, Illinois
}

\begin{abstract}
Background: Minimally invasive (MIS) techniques have gained considerable attention for the management of degenerative spinal pathologies. However, few studies have compared the outcomes between MIS and open thoracolumbar corpectomies. The purpose of this study was to compare perioperative variables between MIS and open thoracolumbar corpectomy.

Methods: Retrospective review of 33 patients who underwent either an MIS or open thoracolumbar corpectomy by a single surgeon between 2005 and 2012 was performed. Patients were separated into anterior-posterior MIS (MIS AP), anterior-posterior open (AP), and posterior open (P) cohorts. Postoperative narcotic use was converted to oral morphine equivalents (OMEs). Demographics, comorbidity, perioperative variables, complications, and computed tomographic analyses were assessed. Fisher exact test was performed for categorical variables and Student $t$ test for continuous variables. A $P$ value of $\leq .05$ denoted statistical significance.

Results: Thirty-three patients underwent an MIS AP, AP, or P thoracolumbar corpectomy (39.4\% vs $15.2 \%$ vs $45.5 \%$, respectively). MIS AP patients were younger with a lower comorbidity burden than either open cohorts. In addition, MIS AP patients demonstrated a decreased procedural time, lower blood loss, and shorter hospitalization than either open cohorts. MIS AP patients required less units of transfusion than P and AP patients while demonstrating lower postoperative narcotics consumption and reoperations rates than open AP patients. Surgical site infection rates, body mass index, intraoperative fluid requirements, and complication rates were similar between cohorts. All patients demonstrated successful arthrodesis at 1 year based upon computed tomography.
\end{abstract}

Conclusions: MIS AP thoracolumbar corpectomy patients incurred decreased procedural times, shorter hospitalization, and lower blood loss compared with open patients. MIS AP patients demonstrated decreased postoperative narcotics consumption and reoperation rates compared with traditional AP patients. All patients demonstrated successful arthrodesis.

Clinical Relevance: The MIS approach to thoracolumbar corpectomies appears to be a safe and efficacious alternative when compared with traditional methods.

Minimally Invasive Surgery

Keywords: corpectomy, thoracolumbar corpectomy, minimally invasive corpectomy, vertebrectomy, MIS corpectomy, tumors

\section{INTRODUCTION}

Pathologies involving the structural integrity of the vertebral bodies can pose a technical challenge for spine surgeons. Traditionally, thoracolumbar corpectomies have been used for a wide range of spinal pathologies including metastatic disease, burst fractures, and osteomyelitis. These procedures facilitate a thorough neural decompression while offering a biomechanically sound stabilization. However, traditional open thoracolumbar techniques have been associated with complication rates as high as $79 \% .^{1-5}$ Posterior-based (extra-cavitary) approaches are associated with incomplete visuali- zation of the anterior structures, which can lead to unsatisfactory decompression and instrumentation. ${ }^{6,7}$

Minimally invasive (MIS) techniques for spine surgery has demonstrated decreased blood loss, reduced postoperative pain, shorter hospitalization, and lower infection rates in the setting of degenerative spinal conditions. ${ }^{8-10}$ However, evidence for the use of MIS corpectomies via a limited anteriorposterior (AP) approach has been limited to small series with heterogeneous populations. As such, the purpose of this study is to compare the perioperative outcomes, complications, and fusion rates between MIS and traditional open thoracolumbar corpec- 
tomies for conditions including tumor, infection, and trauma.

\section{METHODS AND MATERIALS}

\section{Patient Population}

Internal institutional review board approval was obtained to retrospectively review a prospectively maintained registry for all patients who underwent a single-level thoracolumbar corpectomy by a single surgeon between 2005 and 2012. All patients presented with nonmechanical pain, dynamic instability, or neurologic compression (ie, radiculopathy, myelopathy, or myeloradiculopathy). Patients with hemicorporectomies, cervical pathologies, sacral pathologies, revision surgeries, and less than 2-year follow-up were excluded. Patients were stratified by surgical approach into MIS AP, open AP, and open posterior $(\mathrm{P})$ cohorts.

\section{Perioperative Characteristics}

Preoperative patient demographics, comorbidity burden, body mass index (BMI), vertebral level, and diagnosis were compared. Patient comorbidity burden was assessed via a modified Charlson Comorbidity Index (CCI). ${ }^{11}$ These modifications included (1) a history of myocardial infarction was omitted, and (2) liver disease was given an adjusted weight of 2 points rather than 1 point for mild disease and 3 points for moderate to severe liver disease. Previous studies have demonstrated that slight modifications to the CCI have minimal impact on the overall score. ${ }^{11,12}$ Intraoperative characteristics such as procedural time, estimated blood loss (EBL), fluid administration, and transfusion rates were recorded. Postoperative hospitalization outcomes such as length of stay, narcotic consumption, and short-term complications were compared. Fusion and reoperation rates were recorded at latest follow-up.

Postoperative opioid consumption data were collected and narcotics were converted to oral morphine equivalents (OMEs) using a standardized calculation in order to account for differences in dosage, potency, and route of administration. The study on opioid equianalgesic calculations by Gordon et $\mathrm{al}^{13}$ was referenced to determine narcotic to oral morphine conversion ratios.

\section{Surgical Technique}

\section{Open AP}

A standard thoracotomy was used with the approach being performed by a board-certified thoracic surgeon using single lung ventilation via a double lumen endotracheal tube. An oblique incision was centered over the pathologic level with the overlying rib (if applicable) being disarticulated and morcellized for bone graft. If necessary, additional bone graft was harvested from the iliac crest. The parietal pleura (at the upper thoracolumbar interface) was opened and split near the costovertebral joint. The lung was retracted anteriorly. A bronchial blocker was used, and the lung was only deflated as needed during the exposure. Resection of the costovertebral joint and rib head allowed anterolateral visualization of the vertebral body. Chest tube placement was required upon closure of the thoracotomy. For retroperitoneal exposures, a direct lateral thoracoabdominal approach was used via formal cutting of the external and internal oblique musculature. The posterior approach consisted of a standard midline exposure with open placement of the pedicle screws and standard decortication of the posterior transverse processes.

\section{Open Posterior}

A standard midline approach was used with a complete laminectomy and facetectomy being performed. The thoracic level exiting nerve root was resected, and a standard extra-cavitary approach was done resecting the vertebral body and the superior and inferior disc space. An expanding articulating cage was then placed via the extracavitary defect with posterior pedicle screws being placed 2 levels above and below the corpectomy site. Iliac crest bone graft was used for the majority of cases.

\section{MIS Anterior-Posterior (MIS AP)}

Appropriate preoperative imaging was analyzed (Figure 1a-1e). The patient was placed in the lateral decubitus position. Following appropriate intraoperative imaging, an oblique incision $(2.5 \mathrm{~cm}$ in length) was made over the level of pathology. At the lower thoracic or upper lumbar level, the incision was made over the rib. After subperiosteal dissection, a segment of the rib was removed $(2 \mathrm{~cm})$ from the underlying pleura and neurovascular bundle and morcellized for bone graft. When necessary, bone 


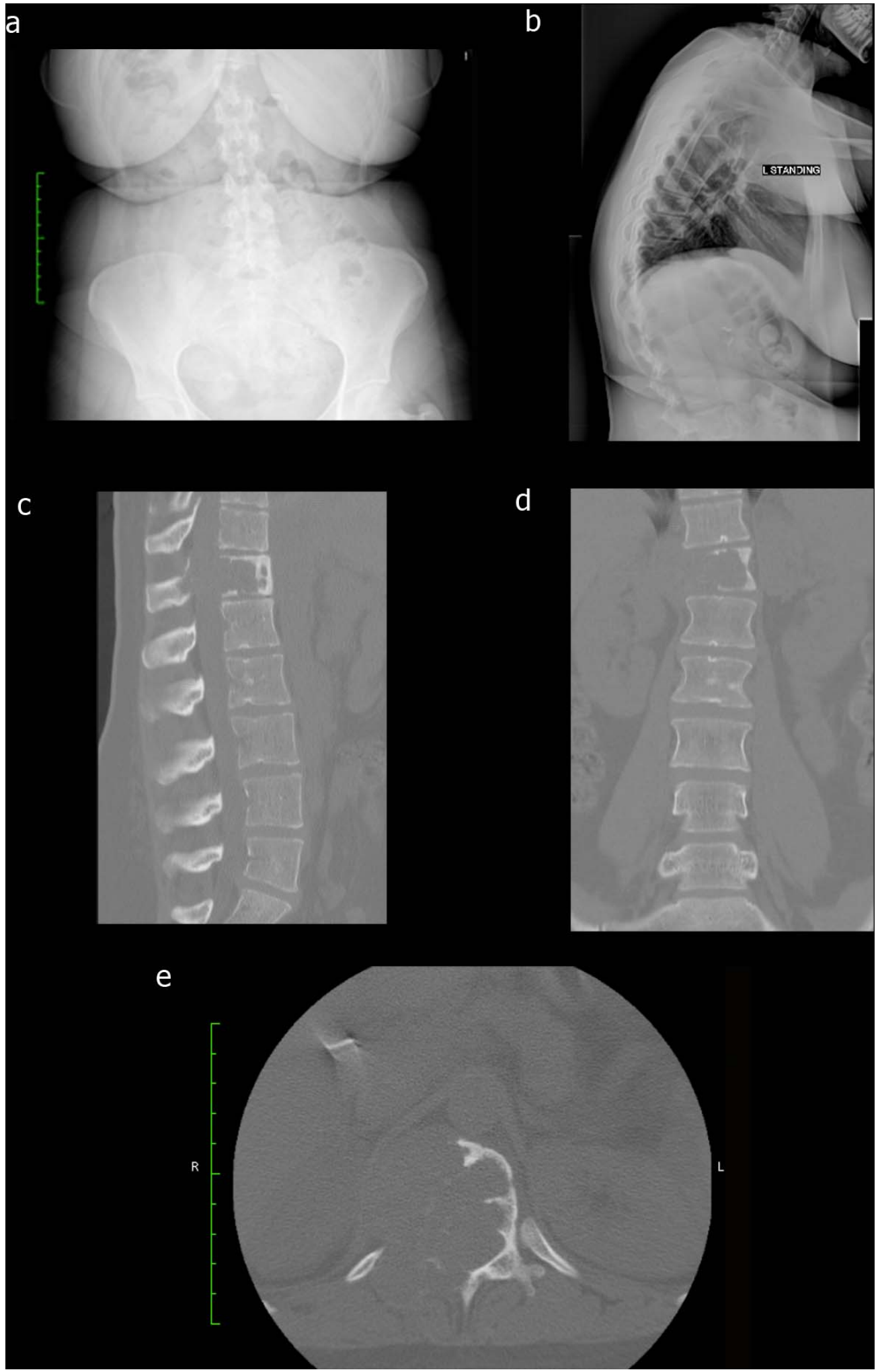

Figure 1. (a) Forty-two-year-old female presents with worsening back pain and thoracic discomfort for the past 3 months. Preoperative anterior-posterior (AP) radiograph demonstrating thoracic deformity secondary to giant cell tumor with complete osteolysis of the pedicle. (b) Preoperative lateral radiograph demonstrating kyphosis secondary to vertebral body destruction secondary to the giant cell tumor. (c) Preoperative sagittal computed tomography (CT) scan demonstrating T12 vertebral body osteolysis secondary to giant cell tumor infiltration. (d) Preoperative coronal CT scan demonstrating thoracic spinal deformity secondary to pathologic burst fracture of the T12 vertebral body. (e) Preoperative axial CT scan demonstrating burst fracture of T12 vertebral body secondary to giant cell tumor infiltration with extension into the spinal canal. 

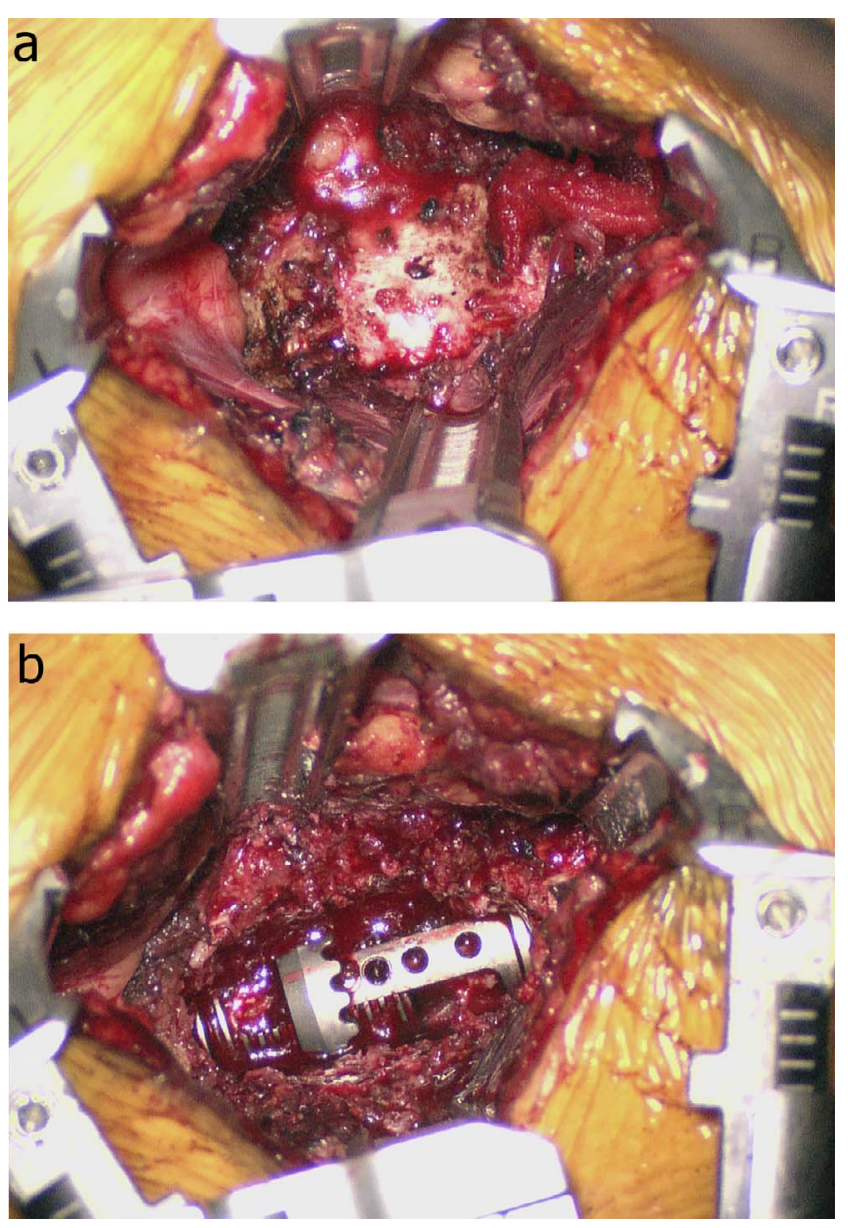

Figure 2. (a) Intraoperative image demonstrating retractors in place with adequate visualization of the T12 vertebral body via minimally invasive (MIS) retropleural subdiaphragmatic approach. (b) Intraoperative image demonstrating completed corpectomy with expandable titanium cage in place.

graft was harvested from the facet joint. For retropleural access (T10-11), the parietal pleura was bluntly swept anteriorly. A bronchial blocker was used, and the lung was only deflated as needed during the exposure and subsequently reinflated once the tubular retractors were placed. For access to T12-L1, an extrapleural subdiaphragmatic approach was undertaken. Anterior exposure of L2-L5 was done through a retroperitoneal, trans-psoas approach. Fixed expandable retractors were placed after dilation (Figure 2a-2b). Real-time neuromonitoring was used throughout the case (lumbar) with specific stimulated monitoring during the approach, retractor adjustments, and instrumentation. Posterior instrumentation was placed percutaneously after repositioning the patient into the prone position on a Jackson table (Figure 3a-3b).

\section{Statistical Methods}

Statistical analysis was performed using an independent sample $t$ test for continuous variables and Fisher exact test for categorical data. An $\alpha$ level of $<.05$ denoted statistical significance. Analyses were performed with SPSS version 20.0 (Prentice Hall, Chicago, Illinois).

\section{RESULTS}

Patient characteristics are described in Table 1. A total of 33 patients were included in the analysis. Of these, $5(15.2 \%)$ open AP, 13 (39.4\%) MIS AP, and 15 (45.5\%) open P patients were identified. The level of corpectomy ranged from T4 to L5. The MIS AP cohort was younger than the open P group (45.1 vs $59.3, P<.05)$ and demonstrated a lower comorbidity burden compared with both open cohorts (CCI 4.15 vs 7.8 and 9.2, $P<.05$ ). Gender, BMI, and metastatic profile were similar between cohorts. In addition, the posterior open $(\mathrm{P})$ cohort was more likely to undergo a corpectomy procedure for tumors when compared with the MIS AP patients. However, no differences were demonstrated in the rate of metastatic disease between the P, MIS AP, and open AP cohorts.

The MIS AP cohort had a decreased operative time (3.9 vs 6.1 vs 6.0 hours, $P<.05$ ), length of hospitalization (5.5 vs 9 vs 11 days, $P<.05$ ), and reduced blood loss (400 vs 2,260 vs $2,275 \mathrm{cc}, P<$ .05 ) compared with the open AP and open $\mathrm{P}$ cohorts, respectively (Table 2). No differences were demonstrated in the rates of intraoperative complications, in-hospital complications, or surgical site infections between all cohorts. However, the narcotic use (OME $540 \pm 259$ vs $1,095 \pm 745, P<.05)$ and the reoperation rate was significantly lower in the MIS AP patients when compared with the open AP cohort. All patients demonstrated radiographic evidence of arthrodesis at the 1-year follow-up based upon computed tomographic imaging (Figure $3 \mathrm{c}-3 \mathrm{~g})$.

The MIS AP patients demonstrated lower transfusion rates than the open $\mathrm{P}$ cohort $(15.4 \%$ vs $80.0 \%, P<.05)$ and the open AP patients $(15.4 \%$ vs $80.0 \%, P<.05$; Table 3$)$. In those patients who received intraoperative transfusions, the MIS AP patients received significantly less units of packed red blood cells $(0.5 \pm 1.1$ vs $2.6 \pm 2.8$ units, $P<$ $.05)$ and fresh frozen plasma (0 vs $0.6 \pm 0.8, P<$ $.05)$. However, no differences were demonstrated in 
Figure 3. (a) Postoperative anterior-posterior (AP) radiograph demonstrating placement of the expandable titanium cage and instrumentation. (b) Postoperative lateral radiograph demonstrating placement of the expandable titanium cage and instrumentation and restoration of normal thoracic kyphosis. (c) Two-year postoperative sagittal computed tomography (CT) scan demonstrating arthrodesis and resolution of deformity without cage migration. (d) Two-year postoperative coronal CT scan demonstrating proper placement of expandable titanium cage with arthrodesis across the graft. (e) Two-year postoperative axial CT scan demonstrating expandable titanium cage with instrumentation and no recurrence of the giant cell tumor. $(f)$ Two-year postoperative sagittal magnetic resonance imaging (MRI) demonstrating placement of expandable titanium cage and decompression of spinal cord without recurrence of the giant cell tumor. (g) Two-year postoperative axial MRI demonstrating placement of expandable titanium cage without recurrence of the giant cell tumor.
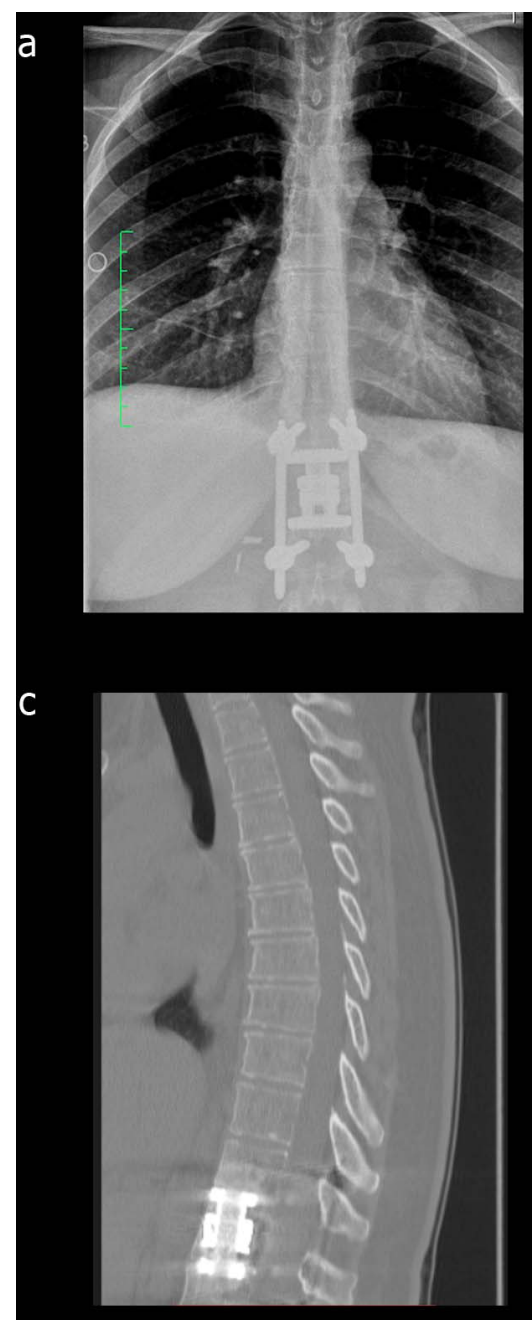

e

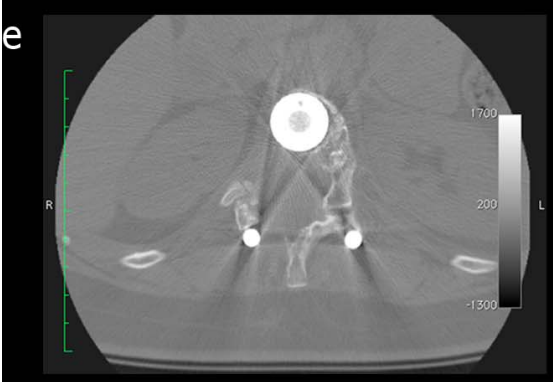

g

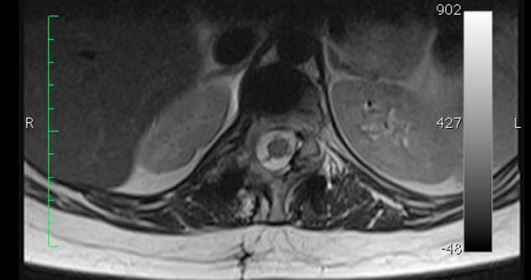

b

d

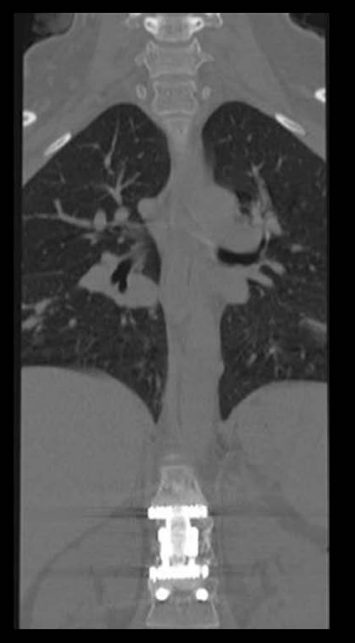

f

E
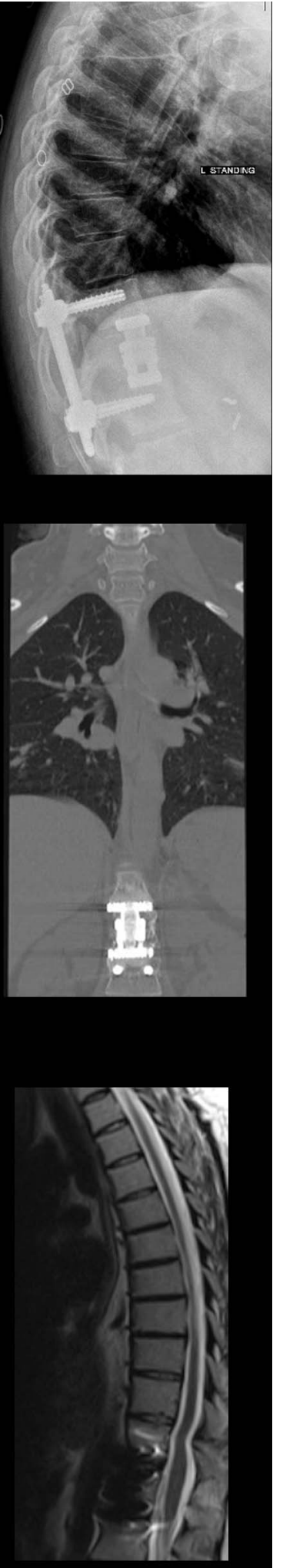
Table 1. Patient characteristics.

\begin{tabular}{|c|c|c|c|c|c|}
\hline & Posterior Open & $P$ Value & MIS AP & $P$ Value & Open AP \\
\hline No. of patients, $\%$ (n) & $100(15)$ & & $100(13)$ & & $100(5)$ \\
\hline$\%$ Female, \% (n) & $53.3(8)$ & .35 & $69.2(9)$ & .81 & $60.0(3)$ \\
\hline Age, mean $\pm \mathrm{SD}, \mathrm{y}$ & $59.3 \pm 17.3$ & $<.05$ & $45.1 \pm 16.2$ & .10 & $59.6 \pm 8.6$ \\
\hline Body mass index, mean $\pm \mathrm{SD}, \mathrm{kg} / \mathrm{m}^{2}$ & $24.4 \pm 2.5$ & .40 & $26.9 \pm 5.8$ & .49 & $24.6 \pm 2.1$ \\
\hline Comorbidity index, mean $\pm \mathrm{SD}$ & $7.8 \pm 4.0$ & $<.05$ & $4.2 \pm 2.7$ & $<.05$ & $9.2 \pm 6.6$ \\
\hline Follow-up period, mean $\pm \mathrm{SD}, \mathrm{y}$ & $1.8 \pm 2.4$ & & $1.5 \pm 1.0$ & & $4.8 \pm 3.2$ \\
\hline Primary diagnosis, \% (n) & & $<.05$ & & .86 & \\
\hline Tumor & $73.3(11)$ & & $46.2(6)$ & & $60.0(3)$ \\
\hline Trauma & $6.7(1)$ & & $46.2(6)$ & & $40.0(2)$ \\
\hline Infection & $20.0(3)$ & & $7.6(1)$ & & 0 \\
\hline Metastatic disease, \% (n) & & .57 & & .21 & \\
\hline Yes & $40.0(6)$ & & $30.8(4)$ & & $60.0(3)$ \\
\hline No & $60.0(9)$ & & $69.2(9)$ & & $40.0(2)$ \\
\hline
\end{tabular}

Abbreviations: MIS AP, minimally invasive anterior-posterior corpectomy; open AP, open technique for anterior-posterior corpectomy; SD, standard deviation. Bold indicates statistical significance.

the amount of postoperative packed red blood cells transfused between the cohorts.

\section{DISCUSSION}

The current study attempted to compare outcomes between traditional means of thoracolumbar corpectomy and less invasive techniques. Despite the small and heterogeneous population, it appears MIS AP corpectomies can be as safe and effective in providing adequate decompression and stabilization for a variety of pathologies without the morbidity associated with traditional open techniques. The results demonstrated in the current study have been consistent with other studies regarding MIS corpectomies. ${ }^{14-16}$ Uribe et $\mathrm{al}^{16}$ analyzed outcomes following a mini-open lateral approach for the management of thoracic spine tumors. Their rates of postoperative complications for MIS, traditional AP, and traditional $\mathrm{P}$ approaches were $4.8 \%, 6.9 \%$, and $11.1 \%$, respectively. ${ }^{16}$ Additionally, the authors found that the less invasive approach offered similar access compared with the open anterior approach without the need for single-lung ventilation or extensive rib resection. ${ }^{16}$ Kossman et $\mathrm{al}^{14}$ analyzed the effectiveness of a novel retractor system in 65 patients undergoing MIS corpectomies. The authors demonstrated that the retractor system allowed for improved surgical access when compared with traditional open approaches with no reported cases of postoperative paraplegia, vessel laceration, or infections. $^{14}$

In the current study, the MIS AP patients demonstrated decreased operative time, blood loss,

Table 2. Perioperative and postoperative characteristics.

\begin{tabular}{|c|c|c|c|c|c|}
\hline & Posterior Open & P Value & MIS AP & P Value & Open AP \\
\hline Procedural time, mean $\pm \mathrm{SD}, \mathrm{h}$ & $6.0 \pm 1.8$ & $<.05$ & $3.9 \pm 1.1$ & $<.05$ & $6.1 \pm 2.5$ \\
\hline Estimated blood loss, mean $\pm \mathrm{SD}, \mathrm{mL}$ & $2,275 \pm 1,529$ & $<.05$ & $400 \pm 345$ & $<.05$ & $2,260 \pm 2039$ \\
\hline Length of hospital stay, mean $\pm \mathrm{SD}, \mathrm{d}$ & $11.4 \pm 7.8$ & $<.05$ & $5.5 \pm 2.2$ & $<.05$ & $9.0 \pm 3.7$ \\
\hline \multicolumn{6}{|l|}{ Intraoperative complications, \% (n) } \\
\hline Iliac vein injury $^{\mathrm{a}}$ & 0 & - & 0 & .14 & $20.0(1)$ \\
\hline \multicolumn{6}{|l|}{ In-hospital complications, \% (n) } \\
\hline Pulmonary embolus & $13.3(2)$ & .35 & 0 & - & 0 \\
\hline Atelectasis & 0 & .10 & $15.4(2)$ & .75 & 0 \\
\hline Surgical site infection, $\%$ (n) & & .35 & & .14 & \\
\hline Yes & $13.3(2)$ & & 0 & & $20.0(1)$ \\
\hline No & $86.7(13)$ & & $100(13)$ & & $80.0(4)$ \\
\hline \multicolumn{6}{|l|}{ Narcotic use $^{\mathrm{b}}$} \\
\hline Oral morphine equivalents, mean $\pm \mathrm{SD}$ & $1,214 \pm 1,408$ & .10 & $540 \pm 259$ & $<.05$ & $1,095 \pm 745$ \\
\hline Reoperations, \% (n) & & .35 & & $<.001$ & \\
\hline Total no. of reoperations & $13.3(2)$ & & 0 & & $40.0(2)$ \\
\hline Irrigation and debridement & $13.3(2)$ & & 0 & & $20.0(1)$ \\
\hline Screw and instrumentation revision & 0 & & 0 & & $20.0(1)$ \\
\hline Arthrodesis rate, $\%(\mathrm{n})^{\mathrm{c}}$ & $100(15)$ & - & $100(13)$ & - & $100(5)$ \\
\hline
\end{tabular}

Abbreviations: MIS AP, minimally invasive anterior-posterior corpectomy; open AP, open technique for anterior-posterior corpectomy; SD, standard deviation. Bold indicates statistical significance.

${ }^{a}$ One patient with injury to common iliac and left iliac vein, which were repaired primarily.

barcotic use in the immediate postoperative period.

${ }^{\mathrm{c}}$ Confirmed by computed tomographic (CT) scan imaging. 
Table 3. Transfusion and intraoperative intravenous fluid administration characteristics.

\begin{tabular}{|c|c|c|c|c|c|}
\hline & Posterior Open & $P$ Value & MIS AP & $P$ Value & Open AP \\
\hline Intraoperative IV fluids, mean $\pm \mathrm{SD}, \mathrm{mL}$ & $3,921 \pm 1,228$ & .90 & $3,754 \pm 1,007$ & .70 & $4,000 \pm 2,222$ \\
\hline Transfusion, $\%(\mathrm{n})$ & & $<.001$ & & $<.05$ & \\
\hline Yes & $80.0(12)$ & & $15.4(2)$ & & $80.0(4)$ \\
\hline No & $20.0(3)$ & & $84.6(11)$ & & $20.0(1)$ \\
\hline \multicolumn{6}{|l|}{ Intraoperative transfusion, units, mean $\pm \mathrm{SD}$} \\
\hline PRBC & $2.6 \pm 2.8$ & $<.05$ & $0.5 \pm 1.1$ & .09 & $1.8 \pm 2.5$ \\
\hline FFP & $0.6 \pm 0.8$ & $<.05$ & 0 & .10 & $0.4 \pm 0.8$ \\
\hline Platelets & $0.3 \pm 2.7$ & .10 & 0 & - & 0 \\
\hline \multicolumn{6}{|l|}{ Postoperative transfusion, mean $\pm \mathrm{SD}$, units } \\
\hline PRBC & $1.1 \pm 2.3$ & .40 & $0.3 \pm 0.8$ & .39 & 0 \\
\hline
\end{tabular}

Abbreviations: FFP, fresh frozen plasma; IV, intravenous; MIS AP, minimally invasive anterior-posterior corpectomy; open AP, open technique for anterior-posterior corpectomy; PRBC, packed red blood cell; SD, standard deviation. Bold indicates statistical significance.

and transfusion rates as compared with both open $\mathrm{P}$ and AP cohorts. These benefits have been part of the hallmark benefits of MIS techniques. Similarly, $\mathrm{Lu}$ et $\mathrm{al}^{5}$ demonstrated decreased blood loss and length of hospitalization with similar operative times and complication rates between patients who underwent mini-open and traditional posterior corpectomies. Despite the similar pathologies involved, differences in patient demographics and surgeon experience may confound these findings. Specifically, the open AP and P techniques were performed earlier in the senior surgeon's career, whereas MIS corpectomies were performed later with increasing experience with the MIS technique. As such, the learning curve may have beneficially influenced his results in subsequent MIS cases.

MIS AP patients demonstrated a lower reoperation rate than the open AP cohort. The latter cohort required 2 reoperations for spinal fluid collection and impingement from a malpositioned pedicle screw. However, the low sample size in the cohorts should warrant caution in deriving clinical significance from these findings. Other studies have reported a low overall reoperation rate using a variety of techniques. Snell et $\mathrm{al}^{17}$ analyzed outcomes of 15 patients following a posterior-based thoracolumbar corpectomy over a mean length of 10.6 months. Revision surgery was required in 1 $(7 \%)$ patient due to hardware failure. ${ }^{17}$ Lee et al ${ }^{18}$ reported 4 reoperations due to anterior cage migrations following 19 L5 corpectomies via the open retroperitoneal approach.

In our analysis, MIS AP corpectomy patients consumed less narcotics compared with the open AP cohort. These findings are consistent with the growing body of evidence demonstrating decreased postoperative morbidity and subsequently less narcotic requirements in patients undergoing MIS spine surgery. ${ }^{21-23}$ Proper postoperative pain man- agement has been associated with expeditious recovery and prevention of chronic pain. ${ }^{19,20}$ Schwender et $\mathrm{al}^{23}$ assessed narcotic use in 49 patients who underwent an MIS transforaminal lumbar interbody fusion (TLIF). The authors demonstrated that these patients achieved narcotic independence by 2 to 4 weeks following surgery. ${ }^{23}$ In addition, Adogwa et $\mathrm{al}^{21}$ demonstrated that MIS TLIF patients ceased narcotic use 2 weeks earlier than the open TLIF cohort. The present study is the largest of its kind to compare narcotic consumption between patients undergoing corpectomies via the 3 techniques.

Arthrodesis rates between the cohorts were similar. Each patient underwent a computed tomography scan as part of the senior surgeon's postoperative protocol. All patients demonstrated complete bridging of bone as confirmed by computed tomography scan at 1 year. Snell et $\mathrm{al}^{17}$ demonstrated no pseudarthrosis at a mean of 10.6 months following open posterior-based thoracolumbar corpectomy in 15 patients. In contrast, Hofstetter et $\mathrm{al}^{24}$ demonstrated an arthrodesis rate of only $68 \%$ in 67 patients with either traumatic or osteomyelitic fractures. Again, the small cohort restricts any conclusions that could be made regarding fusion rates between techniques.

The MIS AP approach does have drawbacks. The technique is associated with a significant learning curve. The difficulty is compounded by a long working distance and narrow surgical working space through a tubular retractor. ${ }^{16}$ Additionally, the technique requires extensive familiarity with the anatomy as standard anatomical landmarks may not be visible for reference. ${ }^{16}$ Finally, the MIS AP corpectomy relies heavily on intraoperative fluoroscopic imaging, which may increase the radiation exposure to the patient and surgical team. 
There were several limitations to this study. First, the sample size of each cohort was relatively small and the study was nonrandomized. This would imply selection bias. However, there were no differences in the diagnoses or levels undergoing corpectomy between cohorts. In addition, the study was underpowered to address certain clinical outcomes such as complication rates or healthrelated quality of life. However, the present study remains one of the larger comparisons of MIS and traditional corpectomies. Second, these procedures were performed by a single spine surgeon. As such, these findings may not be generalizable to all spine procedures in all regions of the United States. Third, the differences in perioperative outcomes may be associated with the younger age and lower comorbidity burden in the MIS AP cohort. Finally, patients underwent a corpectomy for mainly metastatic disease, trauma, and infection. Unquestionably, larger studies are warranted; however, these pathologies are heterogeneous in nature and far from ubiquitous.

The findings of the present study suggest that MIS AP thoracolumbar corpectomies are a viable alternative to traditional approaches. Benefits include decreased procedural times, hospitalization, narcotic use, and blood loss without increasing complications or compromising fusion rates. Further studies should focus on detailed and long-term health-related quality of life outcomes for patients undergoing MIS techniques for traditionally morbid pathologies.

\section{REFERENCES}

1. Capener N. The evolution of lateral rhachotomy. $J$ Bone Joint Surg Br. 1954;36-b(2):173-179.

2. Larson SJ, Holst RA, Hemmy DC, et al. Lateral extracavitary approach to traumatic lesions of the thoracic and lumbar spine. J Neurosurg. 1976;45(6):628-637.

3. McCormick PC. Retropleural approach to the thoracic and thoracolumbar spine. Neurosurgery. 1995;37(5):908-914.

4. Gokaslan ZL, York JE, Walsh GL, et al. Transthoracic vertebrectomy for metastatic spinal tumors. J Neurosurg. 1998;89(4):599-609.

5. Lu DC, Chou D, Mummaneni PV. A comparison of miniopen and open approaches for resection of thoracolumbar intradural spinal tumors. J Neurosurg Spine. 2011;14(6):758764.

6. Bilsky $\mathrm{MH}$, Boland $\mathrm{P}$, Lis $\mathrm{E}$, et al. Single-stage posterolateral transpedicle approach for spondylectomy, epidural decompression, and circumferential fusion of spinal metastases. Spine. 2000;25(17):2240-2249; discussion 250.

7. Wiggins GC, Mirza S, Bellabarba C, et al. Perioperative complications with costotransversectomy and anterior ap- proaches to thoracic and thoracolumbar tumors. Neurosurg Focus. 2001;11(6):e4. doi:10.3171/foc.2001.11.6.5

8. Lall RR, Smith ZA, Wong AP, et al. Minimally invasive thoracic corpectomy: surgical strategies for malignancy, trauma, and complex spinal pathologies. Minim Invasive Surg. 2012;2012:213791. doi:10.1155/2012/213791

9. Oppenheimer JH, DeCastro I, McDonnell DE. Minimally invasive spine technology and minimally invasive spine surgery: a historical review. Neurosurg Focus. 2009;27(3):E9.

10. Park MS, Deukmedjian AR, Uribe JS. Minimally invasive anterolateral corpectomy for spinal tumors. Neurosurg Clin N Am. 2014;25(2):317-325.

11. Charlson ME, Pompei P, Ales KL, et al. A new method of classifying prognostic comorbidity in longitudinal studies: development and validation. J Chronic Dis. 1987;40(5):373-383.

12. Cleves MA, Sanchez N, Draheim M. Evaluation of two competing methods for calculating Charlson's comorbidity index when analyzing short-term mortality using administrative data. J Clin Epidemiol. 1997;50(8):903-908.

13. Gordon DB, Stevenson KK, Griffie J, et al. Opioid equianalgesic calculations. J Palliative Med. 1999;2(2):209-218.

14. Kossmann T, Jacobi D, Trentz O. The use of a retractor system (SynFrame) for open, minimal invasive reconstruction of the anterior column of the thoracic and lumbar spine. Eur Spine J. 2001;10(5):396-402.

15. Payer M, Sottas C. Mini-open anterior approach for corpectomy in the thoracolumbar spine. Surgical Neurol. 2008;69(1):25-31; discussion -2.

16. Uribe JS, Dakwar E, Le TV, et al. Minimally invasive surgery treatment for thoracic spine tumor removal: a miniopen, lateral approach. Spine. 2010;35(26 suppl):S347-S354.

17. Snell BE, Nasr FF, Wolfla CE. Single-stage thoracolumbar vertebrectomy with circumferential reconstruction and arthrodesis: surgical technique and results in 15 patients. Neurosurgery. 2006;58(4 suppl 2):ONS-263-268; discussion ONS-9.

18. Lee YP, Ghofrani H, Regev GJ, et al. A retrospective review of long anterior fusions to the sacrum. Spine $J$. 2011;11(4):290-294.

19. Oderda G. Challenges in the management of acute postsurgical pain. Pharmacotherapy. 2012;32(9 suppl):6s-11s.

20. Perkins FM, Kehlet H. Chronic pain as an outcome of surgery. A review of predictive factors. Anesthesiology. 2000;93(4):1123-1133.

21. Adogwa O, Parker SL, Bydon A, et al. Comparative effectiveness of minimally invasive versus open transforaminal lumbar interbody fusion: 2-year assessment of narcotic use, return to work, disability, and quality of life. $J$ Spinal Disord Tech. 2011;24(8):479-484.

22. Parker SL, Lerner J, McGirt MJ. Effect of minimally invasive technique on return to work and narcotic use following transforaminal lumbar inter-body fusion: a review. Prof Case Manag. 2012;17(5):229-235.

23. Schwender JD, Holly LT, Rouben DP, et al. Minimally invasive transforaminal lumbar interbody fusion (TLIF): technical feasibility and initial results. $J$ Spinal Disord Tech. 2005;18(suppl):S1-S6.

24. Hofstetter CP, Chou D, Newman CB, et al. Posterior approach for thoracolumbar corpectomies with expandable cage placement and circumferential arthrodesis: a multicenter 
case series of 67 patients. J Neurosurg Spine. 2011;14(3):388397.

Disclosures and COI: The authors received no funding for this study and report no conflicts of interest.

Corresponding Author: Kern Singh, MD, Associate Professor, Department of Orthopaedic Surgery, Rush University Medical Center, $1611 \mathrm{~W}$ Harrison St, Suite \#300, Chicago, IL 60612. Phone:
(312) 432-2373; Fax: (708) 492-5373; Email: kern. singh@rushortho.com.

Published 11 November 2020

This manuscript is generously published free of charge by ISASS, the International Society for the Advancement of Spine Surgery. Copyright (C) 2020 ISASS. To see more or order reprints or permissions, see http://ijssurgery.com. 